\title{
Microbial community dynamics of a blue-veined raw milk cheese from the United Kingdom
}

\author{
Dewi Yunita* $\dagger^{1}$ and Christine E. R. Dodd* \\ *Division of Food Sciences, School of Biosciences, University of Nottingham, Sutton Bonington Campus, Loughborough, \\ Leicestershire LE12 5RD, United Kingdom \\ †Department of Agricultural Product Technology, Faculty of Agriculture, Syiah Kuala University, Darussalam, Banda Aceh 23111, Indonesia
}

\section{ABSTRACT}

A commercial blue-veined cheese made from unpasteurized milk was examined by conventional culturing and PCR denaturing gradient gel electrophoresis analysis of the bacterial community $16 \mathrm{~S}$ rRNA genes using 3 primer sets, V3, V4V5, and V6V8. Genomic DNA for amplification was extracted directly from raw milk, starter culture, cheese at different stages of production, fully ripened cheese, and from the cultured cells grown on various media. The outer rind was sampled separately from the inner white core and blue veins. A diverse microbiota containing Lactococcus lactis ssp. lactis, Lactobacillus plantarum, Lactobacillus curvatus, Staphylococcus gallinarum, Staphylococcus devriesei, Microbacterium sp., Sphingobacterium sp., Mycetocola sp., Brevundimonas sp., Enterococcus faecalis, Proteus sp., and Kocuria sp. was detected in the raw milk using culturing methods, but only Lactococcus lactis ssp. lactis, Lactobacillus plantarum, and Enterococcus faecalis survived to the final cheese and were detected both in the core and the rind. Using PCR denaturing gradient gel electrophoresis analysis of the cheese process samples, Staphylococcus equorum and Enterococcus durans were found in the rind of prepiercing samples but not in the core and veins; after piercing, these species were found in all parts of the cheese but survived only in the rind when the cheese was fully ripened. Brevibacterium sp., Halomonas sp., Acinetobacter sp., Alkalibacterium sp., and Corynebacterium casei were identified only by PCR denaturing gradient gel electrophoresis and not cultured from the samples. Brevibacterium sp. was initially identified in the cheese postpiercing (core and veins), Halomonas sp. was found in the matured cheese (rind), and Acinetobacter sp., Alkalibacterium sp., and Corynebacterium casei were also found in the prepiercing samples (rind) and then found through the

Received November 6, 2017.

Accepted February 10, 2018.

${ }^{1}$ Corresponding author: dewi_yunita@unsyiah.ac.id subsequent process stages. The work suggests that in this raw milk cheese, a limited community from the milk survive to the final cheese, with salt addition and handling contributing to the final cheese consortium.

Key words: raw milk, blue-veined cheese, PCR denaturing gradient gel electrophoresis (DGGE), microbial diversity

\section{INTRODUCTION}

The most strictly prescribed unpressed blue-veined cheese in the United Kingdom (UK) is Stilton. It is a protected designation of origin product of the counties of Derbyshire, Leicestershire, and Nottinghamshire, with the requirement that milk is pasteurized at the first stage. Since March 1990, a blue-veined raw milk cheese made by the same process as Stilton has been produced commercially in Nottinghamshire. This cheese has the same texture and appearance as Blue Stilton, which has a creamy white curd, open texture with blue-green well-distributed veins (created by piercing the cheese during ripening), and rough brown rind (Scott et al., 1998). Both cheeses use similar lactic cheese starter cultures, consisting of Lactococcus lactis ssp. lactis, Lactococcus lactis ssp. cremoris, and Lactococcus lactis ssp. lactis bv. diacetylactis. Both cheeses also contain a starter Penicillium roqueforti mold that starts to grow in the core of the cheese after the piercing process, due to the aerobic conditions this creates, giving the bluevein appearance of the cheese that develops during the ripening period (Bockelmann, 2010).

The microbial community of Stilton has been previous studied and shown to present a complex consortium of bacteria (Ercolini et al., 2003) and yeasts (Gkatzionis et al., 2014). This nonstarter microbiota varies in the different parts of the cheese (white core, blue veins, and outer rind) and has been shown to contribute to the flavor volatile production, which also shows variation in the different regions of the cheese (Gkatzionis et al., 2013, 2014; Price et al., 2014); however, no work has been published on raw milk blue-veined cheese originally from the UK. The nonstarter microbiota may differ 
as the microorganisms in the raw milk will be different, coming from the cow and milking environment, and these may contribute to the final cheese community and determine sensory properties.

There is much debate among cheese makers on the use of raw or pasteurized milks for cheesemaking. The risks and benefits for traditional cheeses, mainly raw milk cheeses, have been discussed by Montel et al. (2014). The concern over use of unpasteurized milk in cheese production is related to health concerns caused by pathogenic bacteria such as Salmonella, Campylobacter, Brucella, Shiga-toxin producing Escherichia coli, Listeria monocytogenes, and Shigella found in cheeses (Gould et al., 2014). Pasteurization is usually used to ensure the safety of milk and is the reason why Stilton cheesemakers use pasteurized milk. However, for raw milk cheesemakers, pasteurization kills desirable bacteria and destroys enzymes and proteins, resulting in a less tasty cheese. The safety risks of raw milk can be addressed, however, as fermentation should kill pathogenic bacteria if it is done properly. Thus, the main concern of traditional cheese producers is to preserve microbial diversity and exploit its benefits.

Therefore, in the current study, we analyzed the bacterial diversity during raw milk blue-veined cheese production using a traditional culture approach and 16S rRNA gene PCR denaturing gradient gel electrophoresis (DGGE) techniques to evaluate the bacteria that contribute to production of the characteristics of the product. The presence of Lactococcus lactis at the end of production has also been examined by pulsedfield gel electrophoresis (PFGE) to determine whether its origin was from the raw milk or the added starter cultures. This should create an understanding of raw milk cheese production and the microbiota components needed to allow cheesemakers to create a consistent product.

\section{MATERIALS AND METHODS}

\section{Sampling}

The UK blue-veined raw milk cheese is made from unpasteurized milk. The process is started by pouring the milk into a stainless steel tank, heating to $30^{\circ} \mathrm{C}$, adding starter cultures (Lactococcus lactis and Penicillium roqueforti), and 90 min later adding rennet. The mixture is fermented at around 30 to $40^{\circ} \mathrm{C}$. After $6 \mathrm{~h}$, the curds form and are cut by hand into small cubes to release the whey. The soft curds are transferred manually by ladles into a second tank and left overnight. The curds are milled, salted, and poured into plastic cylindrical hoops without pressing. Cheeses are then left in the hastener $\left(21^{\circ} \mathrm{C}\right)$ and turned daily for $5 \mathrm{~d}$ to allow the whey to drain. On the fifth day, the cheeses are removed from the hoops and the outside smoothed by knives in a process termed rubbing up. The cheeses are then moved to the ripening rooms $\left(13^{\circ} \mathrm{C}\right.$, relative humidity $=85 \%$ ), and $6 \mathrm{wk}$ later fresh cheese is pierced by stainless steel needles to allow development of the blue veins. Finally, after around another 6 wk $\left(13^{\circ} \mathrm{C}\right.$, relative humidity $=90 \%$ ), the cheeses are fully matured.

Samples from bulk raw milk, frozen starter culture, and a raw milk blue-veined cheese during production were taken aseptically in the spring season in Nottinghamshire. The production sites sampled were premilling, postmilling and salting, prepiercing (6 wk), postpiercing (9 wk), and fully ripened cheese (12 wk). The raw milk sample was processed immediately after collecting, but the frozen starter culture was left overnight at room temperature (at around $20^{\circ} \mathrm{C}$ ) to thaw following the manufacturer's procedure for use in cheese production. The rest of the samples were analyzed within $6 \mathrm{~h}$ or kept cool at $4^{\circ} \mathrm{C}$ for no longer than $24 \mathrm{~h}$. For all cheese samples, the outer rind was separated from the inner core of the cheese and the 2 regions were tested separately. The inner core was collected using a sterilized cheese corer. All samples were obtained in triplicate.

\section{Microbiological Analysis}

The cheese samples (25 g) were weighed into a stomacher bag, diluted in quarter-strength Ringer's (225 $\mathrm{mL}$; Oxoid, Basingstoke, UK), and homogenized in a stomacher at $230 \mathrm{rpm}$ for 2 min (Stomacher 400 Circulator, Seward, West Sussex, UK). These samples were considered as the $10^{-1}$ dilution and were further diluted to $10^{-8}$ by 10 -fold serial dilutions in the same diluent. Milk and starter culture samples were directly diluted in quarter-strength Ringer's. Samples $(0.1 \mathrm{~mL})$ of each dilution were spread-plated in triplicate on nonselective and selective media. Mesophilic aerobic bacteria were counted on brain heart infusion (BHI) agar, yeasts and molds on rose bengal chloramphenicol agar (RBCA), lactococci on M17 agar, lactobacilli on Rogosa agar, lactic acid bacteria (LAB) on MRS agar, enterococci on KF Streptococcal agar (KFSA), and staphylococci on Baird Parker (BP) agar. All agars were from Oxoid. All bacterial plates were incubated at $30^{\circ} \mathrm{C}$ for $2 \mathrm{~d}$, whereas yeasts and molds were grown at $25^{\circ} \mathrm{C}$ for $5 \mathrm{~d}$. The LAB and lactobacilli were incubated under anaerobic conditions, which were obtained by using AnaeroGen Gas Pack (Oxoid; Conte et al., 2011). Presumptive Staphylococcus aureus from BP agar were confirmed by catalase (using $40 \% \mathrm{H}_{2} \mathrm{O}_{2}$ ) and coagulase tests (Staphytect Plus Test, Oxoid; Collins et al., 2004). 


\section{Selection and Characterization of Isolates}

To analyze the cultured populations, a total of 80 isolates (41 isolates from the mature cheese and 39 isolates from raw milk) with different colony types were randomly picked from the 7 media used. Each isolate was purified by streak-plating 3 times and stored in Microbank Bacterial and Fungal Preservation System (Pro-Lab Diagnostic, Wirral, UK) at $-80^{\circ} \mathrm{C}$. Isolates were examined for cell morphology by Gram staining and for their ability to grow at $10^{\circ} \mathrm{C}$ for $4 \mathrm{~d}$ and $40^{\circ} \mathrm{C}$ for $2 \mathrm{~d}$.

\section{DNA Extraction}

Bulk cell suspensions were collected from the culture plates by adding $1 \mathrm{~mL}$ of sterile PBS (Oxoid) onto the confluent growth plates $\left(10^{-1}\right.$ dilution). A DNeasy Mericon Food Kit (Qiagen, Hilden, Germany) was used to extract DNA from cheese, milk, and bulk cell suspensions. The following procedure was used with some modification of the manufacturer's instructions (Qiagen, 2018). Briefly, the cheese sample (200 mg), milk sample $(0.2 \mathrm{~mL})$, or bulk cell suspension $(0.2 \mathrm{~mL})$ was placed into a sterile 1.5 -mL microcentrifuge tube, then $1 \mathrm{~mL}$ of Food Lysis Buffer (cetyltrimethylammonium bromide) and $2.5 \mu \mathrm{L}$ of proteinase $\mathrm{K}$ solution were added. The mix was incubated for $30 \mathrm{~min}$ at $60^{\circ} \mathrm{C}$ in a thermomixer (Eppendorf, Hamburg, Germany) at $1,000 \mathrm{rpm}$, followed by cooling for $1 \mathrm{~min}$ and centrifuging at $10,000 \times g$ for $5 \mathrm{~min}$ at room temperature. The clear supernatant $(700 \mu \mathrm{L})$ was placed into a new tube containing $500 \mu \mathrm{L}$ of chloroform (Fisher Scientific, Hampton, NH), then the mix was vortexed for $15 \mathrm{~s}$ and centrifuged at $14,000 \times g$ for $15 \mathrm{~min}$ at room temperature. The upper solution $(250 \mu \mathrm{L})$ and $1 \mathrm{~mL}$ of Buffer PB (5 M guanidine hydrochloride and 30\% isopropanol) were mixed thoroughly in a new tube by vortexing, then transferred into the QIAquick spin column before centrifuging at $17,000 \times g$ for $1 \mathrm{~min}$ at room temperature. Buffer AW2 (a low-salt buffer, $500 \mu \mathrm{L}$ ) was added onto the column and this was centrifuged at $17,000 \times$ $g$ for $1 \mathrm{~min}$ at room temperature. The flow-through was discarded and the column was centrifuged again at $17,000 \times g$ for $1 \mathrm{~min}$ at room temperature. Finally, the column was transferred into a new tube and $100 \mu \mathrm{L}$ of buffer EB (10 m $M$ Tris-Cl, pH 8.5) was added. The mix was incubated at room temperature for $1 \mathrm{~min}$ before it was centrifuged at $17,000 \times g$ for $1 \mathrm{~min}$ at room temperature to elute the DNA.

The DNA was extracted from reference strains (Lactococcus lactis NCIMB 9918, Lactococcus lactis NCIMB 8763, Lactobacillus plantarum NCIMB 138914, Enterococcus faecalis NCTC 775, and Leuconostoc mes- enteroides; University of Nottingham, Division of Food Sciences strain collection) and pure isolates selected from cheese by a boiling procedure used to lyse the cells in a heating thermocycler. The procedure followed Cocolin et al. (2001).

The extracted DNA $(2 \mu \mathrm{L})$ concentration and purity were measured at a wavelength of $260 \mathrm{~nm}$ by Nanodrop (ND-1000 spectrophotometer, Thermo Scientific, Wilmington, DE). A ratio of absorbance at $260 \mathrm{~nm}$ and $280 \mathrm{~nm}(260 / 280)$ of 1.8 is generally accepted as pure for DNA, as lower ratios indicate the presence of protein, phenols, or other contaminants (NanoDrop Technologies Inc., 2007). The extracted DNA $(1.5 \mu \mathrm{L})$ was then used as template in PCR reactions.

\section{PCR Amplification}

The V3, V4V5, and V6V8 regions of 16S rRNA genes were amplified by PCR, as previously reported (Muyzer et al., 1993; Nübel et al., 1996; Schwieger and Tebbe, 1998). For DGGE analysis, a GC-clamp was added to each forward primer (Muyzer et al., 1993); PCR amplification was performed with DreamTaq Green PCR Master Mix $(2 \times$; Fermentas, Yorkshire, UK) in a programmable heating thermocycler (BioRad C1000TM Thermal Cycler, Watford, UK). Nuclease-free water $(23.3 \mu \mathrm{L}$; Fermentas), $0.1 \mu \mathrm{L}$ of each primer (MWGBiotech, Ebersberg, Germany), and $1.5 \mu \mathrm{L}$ of sample DNA were added into the master mix $(25 \mu \mathrm{L})$ to give a final volume of $50 \mu \mathrm{L}$. The PCR product $(5 \mu \mathrm{L})$ was checked by electrophoresis on a $1 \%$ TAE agarose gel (agarose 3:1, Melford Laboratories Ltd., Suffolk, UK) containing ethidium bromide $(0.2 \mu \mathrm{g} / \mathrm{mL})$ in $1 \times \mathrm{TAE}$ running buffer ( $40 \mathrm{~m} M$ Tris base, $20 \mathrm{~m} M$ acetic acid, $1 \mathrm{~m} M$ EDTA) at $75 \mathrm{~V}$ for about $45 \mathrm{~min}$. The size of the amplified DNA was determined against a 100-bp molecular weight marker (Promega, Southampton, UK). The gel was imaged under a UV transilluminator (GelDoc XR, BioRad) and gel pictures were recorded using the GelDoc system (The Quantity One 4.6.5 Basic software, Bio-Rad Laboratories).

\section{DGGE Analysis}

Samples of 200-bp PCR products (using V3 primer sets) were analyzed in $8 \%$ (wt/vol) polyacrylamide gels in $1 \times$ TAE buffer, whereas those of 400 bp (using V4V5 and V6V8 primer sets) were run in $6.5 \%$ (wt/vol) polyacrylamide gels (Ercolini et al., 2003). Parallel electrophoresis was performed at $20 \mathrm{~V}$ for $10 \mathrm{~min}$ followed by $16 \mathrm{~h}$ at $50 \mathrm{~V}$ by using a Bio-Rad Dcode apparatus (Universal Mutation Detection System, Bio-Rad Laboratories). The gel contained 20 to $80 \%$ urea formamide, for which $100 \%$ denaturant solutions consisted of $40 \%$ 
(vol/vol) formamide and $7 M$ urea. All DGGE reagents were from Severn Biotech Ltd. (Worcestershire, UK). The gel was stained with GelStar (Lonza, Rockland, $\mathrm{ME}$ ) and the images recorded.

\section{Sequencing of DGGE Bands}

Selected bands were excised from the gel using a sterile scalpel and kept at $4^{\circ} \mathrm{C}$ for $24 \mathrm{~h}$ in $20 \mu \mathrm{L}$ of TE buffer (10 $\mathrm{m} M$ Tris base, $1 \mathrm{mM}$ EDTA; pH 7) to elute DNA into the buffer. The eluted DNA $(1.5 \mu \mathrm{L})$ was reamplified with the same PCR program but without the GC clamp in the respective forward primer. The PCR products $(15 \mu \mathrm{L})$ were purified with Zymoclean Gel DNA Recovery Kit (The Epigenetics Company, Cambridge, UK) according to the manufacturer's procedures (https://www.zymoresearch.com/zymoclean -gel-dna-recovery). Following purification, $15 \mu \mathrm{L}$ of purified DNA was sequenced (MWG Laboratory, Ebersberg, Germany). The DNA sequences were compared with those in public data libraries by using BLAST (Basic Local Alignment Search Tool) search program (http://blast.ncbi.nlm.nih.gov/Blast.cgi).

\section{Preparation of Lactococcus lactis Isolates for PFGE Analysis}

Lactococcus lactis was isolated from 2 commercial starter cultures used alternately by the cheese producers (liquid and powdered) and fully ripened blue-veined raw milk cheese (12 wk). The added starter cultures contained Lactococcus lactis ssp. lactis, Lactococcus lactis ssp. cremoris, and Lactococcus lactis ssp. lactis bv. diacetylactis. The liquid starter culture was used directly for isolation, whereas powdered starter culture was prepared in UHT milk that had been heated at $32^{\circ} \mathrm{C}$ for $24 \mathrm{~h}$ before use following the manufacturer's procedure: $0.1 \mathrm{~g}$ of starter culture (OV100, Orchard Valley Dairy Supplies, Worchestershire, UK) in $10 \mathrm{~mL}$ of heated milk. For the cheese, the rind was also tested separately from the core and blue veins. All samples of each dilution were spread plated $(0.1 \mathrm{~mL}$ in duplicate $)$ and grown aerobically on M17 agar (Oxoid CM 0785) and anaerobically (AnaeroGen kit; Oxoid AN0035A) on MRS agar (Oxoid CM 0361) at $30^{\circ} \mathrm{C}$ for $2 \mathrm{~d}$. Twentyfive isolates were picked from each sample on each media agar and were restreaked twice to get pure isolates for further characterization. Isolates characterized as gram-positive cocci, catalase negative, oxidase negative, and non-group $\mathrm{D}$ were presumptively identified as Lactococcus lactis isolates and were confirmed by sequencing of V3 region. Lactococcus lactis ssp. lactis NCIMB 6681, Lactococcus lactis ssp. cremoris NCIMB 8662, and Lactococcus lactis ssp. lactis bv. diacetylactis
NCIMB 10484 were used as controls. These strains were grown in MRS broth (Oxoid CM0359) at $30^{\circ} \mathrm{C}$ and 100 rpm in a shaking incubator (Gallenkamp, Weiss Technik, Loughborough, UK) for $24 \mathrm{~h}$.

\section{Preparation of Digested Genomic DNA for PFGE Analysis}

Bacterial culture was grown in BHI broth $(3 \mathrm{~mL})$ at $30^{\circ} \mathrm{C}$ in a shaking incubator $100 \mathrm{rpm}$ (Gallenkamp, Weiss Technik) overnight. The cells were then harvested by centrifugation (Eppendorf, Hamburg, Germany) at $13,000 \times g$ for $60 \mathrm{~s}$ at room temperature. In a microcentrifuge tube, the cell pellet was resuspended and washed twice with $1 \mathrm{~mL}$ of TN buffer $[1 \mathrm{M} \mathrm{NaCl}$ (Fisher Scientific S/316/60) and $10 \mathrm{mM}$ Tris-HCl (Sigma T6066, Sigma-Aldrich, St. Louis, MO)] at pH 6.7 by centrifugation (Hettich Zentrifugen Mikro200, Hettich, Boston, MA) at $13,000 \times g$ for $60 \mathrm{~s}$ at room temperature. Resuspended cells $(300 \mu \mathrm{L})$ in TN buffer were warmed to $55^{\circ} \mathrm{C}$ (Thermomixer, Eppendorf) and mixed with $300 \mu \mathrm{L}$ of $1 \%$ (wt/vol) pulse-field certified agarose (BioRad 161-3109) made up in TN buffer. The suspension mixture was poured into a CHEF plug mold (Bio-Rad Laboratories) and allowed to solidify for 15 min at room temperature $\left(20^{\circ} \mathrm{C}\right)$. The embedded cells were lysed with $4 \mathrm{~mL}$ of lysis buffer $[6 \mathrm{~m} M$ Tris- $\mathrm{HCl}$, $0.1 M$ EDTA (Fisher Scientific D/0700/53), and 1\% (wt/vol) $N$-lauryl-sarcosine sodium salt (Sigma L9150), $\mathrm{pH}$ 7.6] containing $10 \mathrm{mg} / \mathrm{mL}$ of lysozyme (Sigma L6876) overnight at $37^{\circ} \mathrm{C}$. The plugs were washed 3 times with $3 \mathrm{~mL}$ of TE buffer $[10 \mathrm{mM}$ Tris- $\mathrm{HCl}$ and 1 $\mathrm{m} M$ EDTA, $\mathrm{pH}$ 7.6] for $30 \mathrm{~min}$ at room temperature, followed by incubation in $4 \mathrm{~mL}$ of proteinase-K buffer [0.5 $M$ EDTA, 1\% (wt/vol) $N$-lauryl-sarcosine sodium salt, and $1 \mathrm{mg} / \mathrm{mL}$ of proteinase-K (Fermentas EO 0491), $\mathrm{pH} 8.5$ ] for $24 \mathrm{~h}$ at $55^{\circ} \mathrm{C}$ (100 rpm; Gallenkamp). The plugs were treated twice with $4 \mathrm{~mL}$ of TE1 buffer (10 $\mathrm{m} M$ Tris- $\mathrm{HCl}$ and $1 \mathrm{~m} M$ EDTA, $\mathrm{pH}$ 8) containing $1 \mathrm{~m} M$ phenylmethylsulfonyl fluoride (Sigma P7626) shaken at $100 \mathrm{rpm}$ for $1 \mathrm{~h}$ at $55^{\circ} \mathrm{C}$. The addition of phenylmethylsulfonyl fluoride was to obtain vivid, discrete, and clear bands after running the gel (Obszanska et al., 2015). The plugs were finally rinsed 3 times with TE2 buffer (10 $\mathrm{m} M$ Tris- $\mathrm{HCl}$ and $50 \mathrm{~m} M$ EDTA, pH 8) for $30 \mathrm{~min}$ at room temperature. The plugs were stored at $4^{\circ} \mathrm{C}$ in TE1 buffer until use.

Before digestion, the DNA plugs were rinsed in 500 $\mu \mathrm{L}$ of sterile distilled water for $15 \mathrm{~min}$ at room temperature, followed by rinsing in $200 \mu \mathrm{L}$ of restriction buffer-D (6 m $M$ Tris- $\mathrm{HCl}, 6 \mathrm{~m} M \mathrm{MgCl}_{2}, 150 \mathrm{~m} M \mathrm{NaCl}$, $1 \mathrm{~m} M$ dithiothreitol, $\mathrm{pH}$ 7.9; Promega R004A). The digestion was carried out for $24 \mathrm{~h}$ at $37^{\circ} \mathrm{C}$ in a 100 $\mu \mathrm{L}$ of solution consisting of $S m a \mathrm{I}(0.4 \mathrm{U} / \mu \mathrm{L}$; Promega 
R6121), BSA $(0.2 \mu \mathrm{g} / \mu \mathrm{L}$; Promega R396D), and buffer J (1×; Promega R009A). The digested plugs were removed from the reaction reagents and stored at $4^{\circ} \mathrm{C}$ in $0.5 \times$ TBE buffer [ $44.5 \mathrm{~m} M$ Tris-HCl, $44.5 \mathrm{~m} M$ boric acid (Sigma B7901), $1.25 \mathrm{~m} M$ EDTA, pH 8] until use.

\section{PFGE Analysis}

The electrophoresis conditions from Obodai (2006) were followed with minor modifications. Electrophoresis was run in $2 \mathrm{~L}$ of $0.5 \times$ TBE buffer [ $44.5 \mathrm{~m} M$ Tris-HCl, $44.5 \mathrm{~m} M$ boric acid (Sigma B7901), $1.25 \mathrm{~m} M$ EDTA, $\mathrm{pH}$ 8] containing $100 \mu M$ thiourea at $14^{\circ} \mathrm{C}$ for $16 \mathrm{~h}$ at $6 \mathrm{~V} / \mathrm{cm}$ using a counter-clamped homogeneous electrophoresis cell (BioRad). The pulsed time used was 4 to $45 \mathrm{~s}$ and pump pressure was $80 \mathrm{rpm}$. A 50 to $1,000 \mathrm{~kb}$ DNA ladder (Sigma D-2416) was used as a molecular size marker. The DNA was visualized by staining in 100 $\mathrm{mL}$ of sterile distilled water containing $10 \mu \mathrm{L}$ of ethidium bromide (10 mg/mL; Fisher Scientific) for $1 \mathrm{~h}$ at room temperature, followed by destaining in $100 \mathrm{~mL}$ of sterile distilled water for $30 \mathrm{~min}$ at room temperature. The gels were imaged under a UV transilluminator (GelDoc XR, BioRad) and recorded with Quantity One 4.6.5 Basic Gel Doc software (BioRad).

\section{PFGE Cluster and Statistical Analysis}

The PFGE profiles were saved as 150-dpi tiff format and were analyzed using FPquest version 4.5 software (BioRad). Calculation of the similarity of the band profiles and grouping of the PFGE patterns was based on the Dice correlation coefficient and the unweighted pair group method with arithmetic averages (UPGMA) cluster analysis. Calculation of the significance of the PFGE profiles was done by AMOVA GenAlEx 6.5: Genetic Analysis in Excel (Microsoft Corp., Redmond, WA).

\section{RESULTS}

\section{Enumeration of Microbial Population by Plate Counts}

The bacterial populations of the raw milk cheese were enumerated through the different stages of production (Table 1); $\mathrm{pH}$ values were also recorded at each stage. The $\mathrm{pH}$ of the raw milk decreased after starter addition and then changes developed through production. Interestingly, unlike with other mold-ripened cheeses where the $\mathrm{pH}$ of the rind is higher than that of the core because of ammonia produced by a high yeast count (Mounier et al., 2006; Gori et al., 2007) and a high mold count (McSweeney and Fox, 2004), the higher pH of the rind relative to the core of the mature cheese was not associated with a higher total yeast and mold count (RBCA) and in fact was $2 \log _{10} \mathrm{cfu} / \mathrm{g}$ lower. Presumptive Lactococcus counts (M17 agar) increased in the early stages of cheese fermentation, with higher counts developing in the rind than in the core in later production stages. The mature cheese showed similar results. Yeasts and molds were not isolated from the raw milk but became evident after milling and salting; these counts increased through the production stages, with counts highest following piercing at 9 wk. Counts in the rind were always higher than the core, which may reflect oxygen availability; however, the total yeast and mold counts in the rind dropped dramatically in wk 12 of ripening. Presumptive Lactobacillus (Rogosa agar) counts showed similar trends. The LAB (MRS agar), presumptive Staphylococcus (BP agar), and presumptive Enterococcus (KFSA) counts all showed a similar trend, being low in the raw milk, increasing after salting, and peaks in counts seen in the rind at $9 \mathrm{wk}$, with core levels much lower; this difference did not appear to be related to a $\mathrm{pH}$ difference between rind and core samples at this stage and, again, may reflect differences in oxygen availability. These bacterial groups are all recognized as moderately halotolerant and are likely to increase after salt addition through reduction in competition with more halo-sensitive species. The mature cheese showed less or no difference between rind and core when compared with the immature cheese for these counts despite a greater $\mathrm{pH}$ difference between the 2 samples (Table 1 ).

\section{Characterization of Raw Milk and Matured Cheese Bacterial Isolates}

Eighty bacterial isolates were taken from the matured cheese and raw milk culture plates and sequenced (Table 2). The 16S rRNA gene sequencing showed the presence of Lactobacillus curvatus, Staphylococcus gallinarum, Staphylococcus devriesei, Microbacterium sp., Sphingobacterium sp., Mycetocola sp., and Brevundimonas sp. only in the raw milk sample. Conversely, Enterococcus faecalis and Proteus sp. were found only in the matured cheese. Kocuria sp. was detected in the milk and the core of the cheese samples, but not in the rind. Lactococcus lactis ssp. lactis and Lactobacillus plantarum were found in all samples. All isolates, except Proteus sp., could grow at $10^{\circ} \mathrm{C}$, indicating they could grow during the early ripening step of this cheese, which is carried out at around $10^{\circ} \mathrm{C}$. The gram-positive coccal species (with the exception of Staph. gallinarum) showed growth at $40^{\circ} \mathrm{C}$ together with Lactobacillus curvatus, showing that the isolates could grow during the initial milk heat treatment before starter culture 


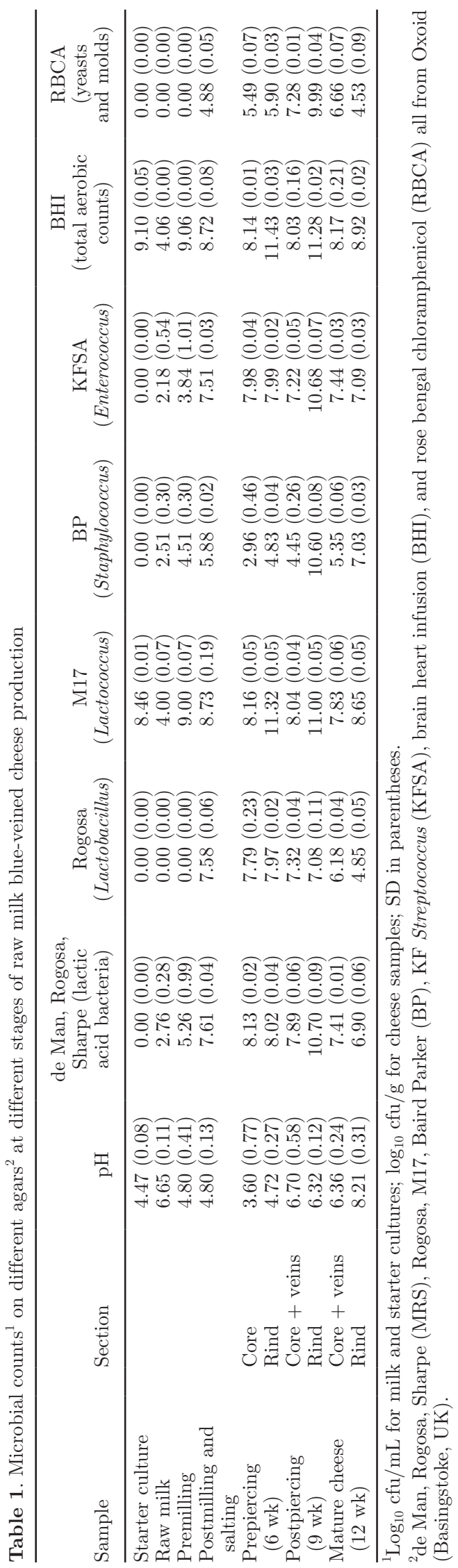

addition and fermentation step, which is carried out at 37 to $40^{\circ} \mathrm{C}$.

It is notable that the M17 medium showed poor selectivity with a range of other gram-positive and gram-negative genera isolated from this medium (Table 2 ). This medium is widely used for isolating and enumerating Lactococcus; however, the counts on M17 cannot be considered to reflect the levels of Lactococcus accurately. In contrast, Rogosa agar, which is used for the enumeration of Lactobacillus, showed much greater selectivity, with Lactobacillus plantarum the main isolate, although Kocuria sp. were also isolated on this medium. Notably $L b$. curvatus was not isolated from Rogosa agar, but only on MRS agar; hence, Rogosa agar may underestimate the Lactobacillus population present.

\section{Bacterial Dynamics During Cheese Production}

We used 3 sets of primers (V3, V4V5, and V6V8) to amplify the variable regions of $16 \mathrm{~S}$ rRNA genes of the bacterial community from samples taken through production of the cheese (Figure 1); bands identified by sequencing are shown marked. The bacterial species detected varied at each production step and with each primer used, with an increase in the diversity in the final cheese. The bacterial species in the rind were more complex than those in the core (Figure 1, V4V5, lanes 10 and 11). In general, Lactococcus lactis ssp. lactis and Lactobacillus sp. were the main representatives in all samples, with Lactococcus (band f) present initially in the raw milk through to the final cheese. Lactobacillus plantarum appeared at the postmilling and salting stages (Figure 1, V3, Lane 5), as suggested by culturing, and was still detected in the fully ripened cheese (Figure 1, V3, Lane 11). Staphylococcus equorum and Enterococcus durans were found in the rind of a prepiercing sample, but not in the core and veins (Figure 1, V3, lanes 6 and 7); after cheese piercing, these species were found in all parts of the cheese, suggesting redistribution by the piercing process (Figure 1, V3, lanes 8 and 9). However, these species only survived in the rind in the final product. Similarly, bands corresponding to Acinetobacter sp., Alkalibacterium sp., and Corynebacterium case $i$ were found in the rind prepiercing (Figure 1, V6V8, lane 7), but only Acinetobacter sp. was detected in the core (Figure 1, V6V8, lane 6). All 3 were present in the core postpiercing, with the first 2 species still detected in the rind postpiercing and in the rind of the mature cheese (Figure 1, V6V8, lanes 9 and 11). However, only Acinetobacter was detected in the core of the mature cheese, suggesting an influence of $\mathrm{pH}$ or oxygen levels. Lactobacillus casei/paracasei, Enterococcus faecalis, and Brevibacterium sp. were only 
found in the rind of the matured cheese, suggesting surface introduction or development of these populations occurs late in production.

A comparison between the MRS, Rogosa, and KFSA cultured populations with the uncultured populations from the mature cheese is shown in Figure 2. Mostly we found the same genera by direct DNA analysis of the culture plates as we identified as purified isolates (Table 2), although the exact species identified showed some variation. In particular, Enterococcus durans and Staphylococcus equorum were found in samples grown on KFSA agar (Figure 2, lane 8) and Lactobacillus casei/ paracasei from MRS and Rogosa agars (Figure 2, lanes 6 and 7); however, these species were not evident from analysis of the DNA extracted directly from the respective cheese samples, suggesting these species were in very low numbers in the cheese itself. Lactococcus lactis was detected in the DNA sample produced by direct extraction from the cheese and was also isolated from M17 and other agars (Table 2). This demonstrated that live Lactococcus lactis cells were still evident in the final cheese. Direct DNA analysis also showed the presence of Brevibacterium in the mature cheese rind, which was not shown by any culture plate analysis.

\section{PFGE Profiles of Lactococcus lactis Isolates}

Twenty-six Lactococcus lactis isolates, which were obtained at different stages of cheese production and confirmed by $16 \mathrm{~S}$ sequencing (Table 2), and 3 Lactococcus lactis controls were subjected to SmaI restriction and PFGE profiling to determine strain relatedness. The SmaI PFGE profiles are shown in Figure 3 together with a dendrogram showing relatedness of the patterns. Lactococcus lactis isolates produced clear profiles and were differentiated into 3 nonoverlapping clusters with 2 out rider strains at $40 \%$ similarity. All isolates from the powdered starter culture were clustered together with 8 isolates from the liquid starter culture, 1 isolate from the cheese rind (CRB11), and Lactococcus lactis ssp. cremoris NCIMB 8662 (cluster 1). Another isolate from the cheese rind (CRB10) clustered with isolates from the liquid starter culture (cluster 2). Two isolates found in the liquid starter culture were similar to Lactococcus lactis ssp. lactis bv. diacetylactis NCIMB 10484 (cluster 3), but not similar with any isolates from the cheese core and veins or rind. Two isolates found in the core and veins of mature cheese (COB20 and COB6) had profiles different from those obtained from the liquid and powdered starter culture isolates. One of these isolates had a similar profile with Lactococcus lactis ssp. lactis NCIMB 6681. This suggests the Lactococcus lactis population originated from several sources. 


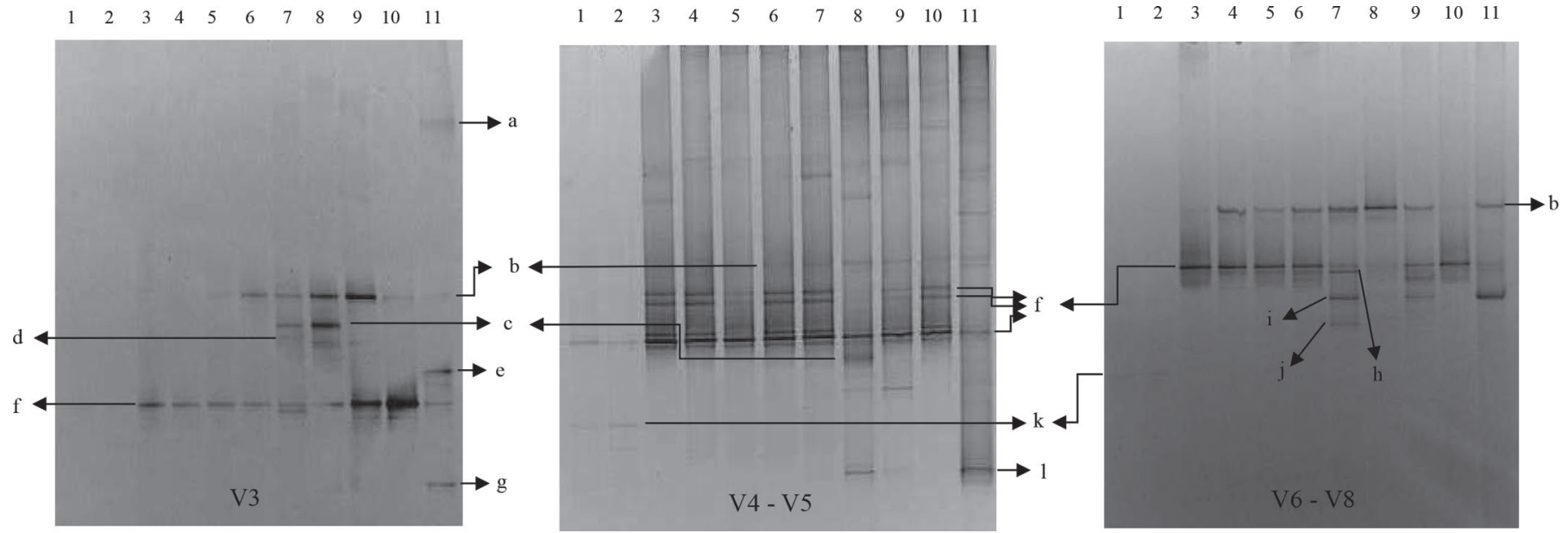

Figure 1. Comparison of bacterial denaturing gradient gel electrophoresis profiles of PCR amplicons of community $16 \mathrm{~S}$ rRNA genes from samples taken at different stages of raw milk blue-veined cheese production using primer sets for 3 different rRNA regions: V3, V4-5, and V6-8. Lanes 1 and $2=$ milk; $3=$ starter culture; $4=$ premilling; $5=$ postmilling and salting; $6=$ prepiercing core and veins; $7=$ prepiercing rind; 8 $=$ postpiercing core and veins; $9=$ postpiercing rind; $10=$ matured cheese (core and veins); $11=$ matured cheese (rind). Bands identified by excision and sequencing: $\mathrm{a}=$ Lactobacillus casei/paracase $; \mathrm{b}=$ Lactobacillus plantarum; $\mathrm{c}=$ Staphylococcus equorum; $\mathrm{d}=$ Enterococcus durans; $\mathrm{e}=$ Enterococcus faecalis $; \mathrm{f}=$ Lactococcus lactis $; \mathrm{g}=$ Brevibacterium $\mathrm{sp} . ; \mathrm{h}=$ Acinetobacter $\mathrm{sp} . ; \mathrm{i}=$ Alkalibacterium $\mathrm{sp} . ; \mathrm{j}=$ Corynebacterium case $; \mathrm{k}=$ Bacillus sp.; $\mathrm{l}=$ Halomonas $\mathrm{sp}$. Gel running conditions are given in Materials and Methods.

\section{DISCUSSION}

In the present study, we examined the bacterial species present during the production of a raw milk mold-ripened cheese by using traditional culturing methods and PCR-DGGE analysis of the variable V3, V4V5, and V6V8 regions of the 16S rRNA genes. This method has previously been used successfully to identify the microbial communities in artisanal Sicilian (Randazzo et al., 2002), Stilton (Ercolini et al., 2003),



Figure 2. Denaturing gradient gel electrophoresis profiles of PCR amplicons of V3 regions of community 16S rRNA genes from samples of mature raw milk blue-veined cheese and cultured cells from culture plates. Lane 1 = mature cheese (core and veins; direct DNA extraction); 2 $=$ cultured cells on de Man, Rogosa, Sharpe (MRS) agar from mature cheese (core and veins); $3=$ cultured cells on Rogosa agar from mature cheese (core and veins); $4=$ cultured cells on KF Streptococcus agar from mature cheese (core and veins); $5=$ mature cheese (rind; direct DNA extraction); $6=$ cultured cells on MRS agar from mature cheese (rind); $7=$ cultured cells on Rogosa agar from mature cheese (rind); $8=$ cultured cells on KFSA agar from mature cheese (rind); $9=$ Lactococcus lactis NCIMB 9918; $10=$ Lactococcus lactis NCIMB 8763; $11=$ Lactobacillus plantarum NCIMB 138914; 12 = Leuconostoc mesenteroides; 13 = Enterococcus faecalis NCTC 775 . Bands were identified by excision and sequencing. Gel running conditions are given in Materials and Methods; all media agar used were from Oxoid (Basingstoke, UK). 
Mozzarella (Ercolini et al., 2004), Cabrales (Flórez and Mayo, 2006), Domiati (El-Baradei et al., 2007), and Lighvan cheeses (Kafili et al., 2009). The use of a nonculture-based approach was chosen to allow all bacterial components present through the cheese production to be identified although these may be in low number or may be cells not readily culturable. Initially 3 different primer sets were used (V3, V45, and V6V8) to examine the bacterial diversity present, as there have been reports of differing sensitivity of these for different bacterial groups (Lorbeg et al., 2009); however, in further analysis, only the V3 primer was used. This primer was chosen because V3 was the best target for discriminating Lactococcus lactis, whereas when using V4V5 this species was detected in a triplet banding pattern that could lead to a bias in interpretation (Figure 1). It is well known that some bacteria produce more than 1 band because a microorganism can contain multiple

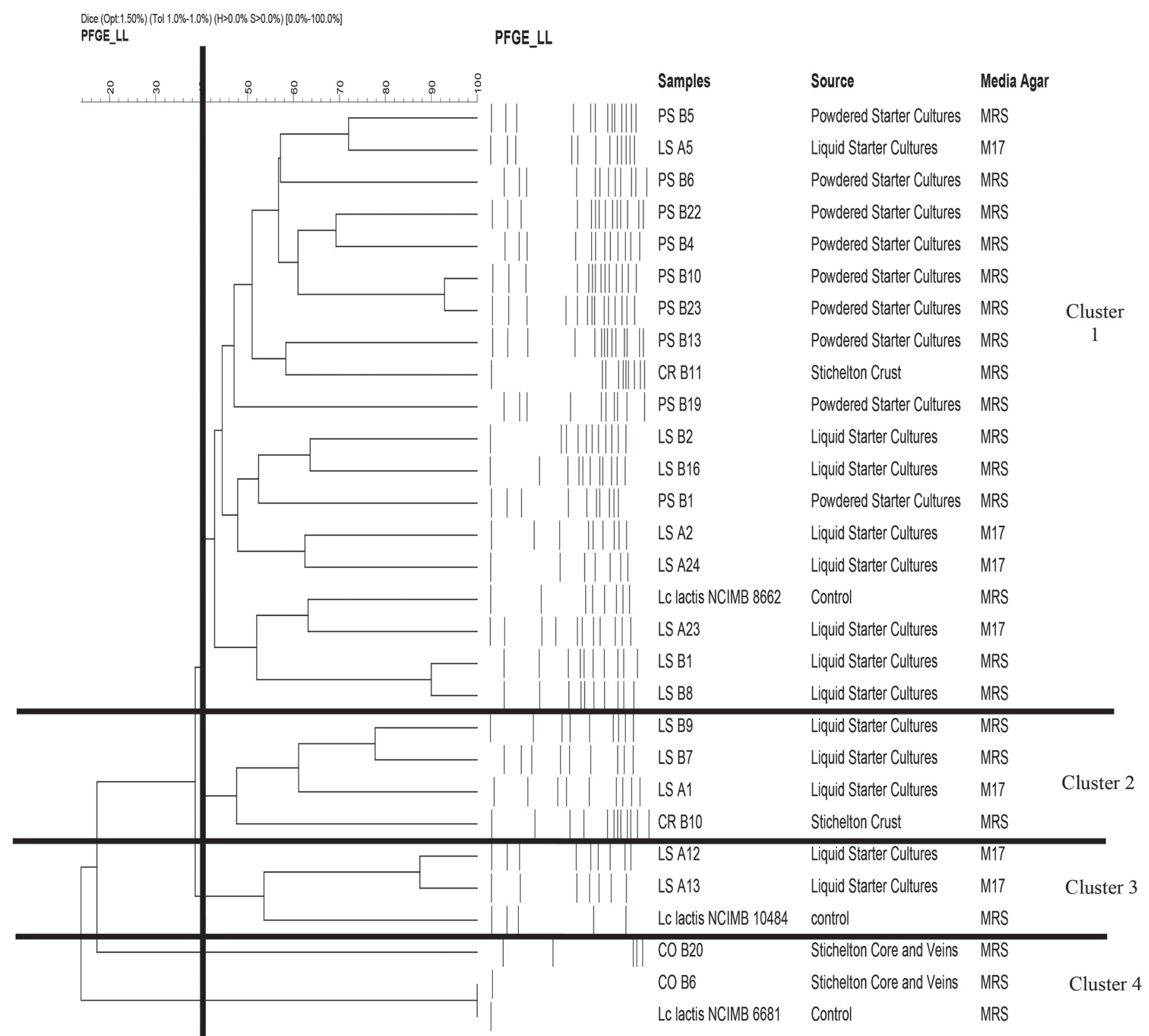

Figure 3. Dendrogram and SmaI restriction patterns of Lactococcus lactis. NCIMB 6681 is the subspecies lactis, NCIMB 8662 is the subspecies cremoris, and NCIMB 10484 is the subspecies lactis bv. diacetylactis. Clustering was performed by the unweighted pair group method with arithmetic averages method. The coefficient of similarity $(40 \%)$ is indicated on the figure by the bold vertical line. PFGE $=$ pulsed-field gel electrophoresis; PS = powdered starter cultures; LS = liquid starter cultures; $\mathrm{CR}=$ cheese crust/rind; CO = cheese core. Stichelton refers to the cheese under study. Media agars used were M17 and de Man Rogosa Sharpe (MRS; Oxoid, Basingstoke, UK). 
rDNA copies of the target gene that are heterogeneous in sequence (Flórez and Mayo, 2006; Kang et al., 2010) and differences in primer target may or may not identify these regions.

Compared with Stilton cheese (Ercolini et al., 2003), the viable counts of bacterial groups of this raw milk cheese were lower on M17, MRS, Rogosa, and BHI agars. A diverse microbiota including Lactobacillus, Enterococcus, and Staphylococcus species was culturable from the mature cheese, with Lactococcus lactis more readily recoverable by culture than was shown from Stilton cheese. This could reflect a differing Lactococcus composition between the 2 cheeses, as the raw milk used contained an existing population that may have differing survival properties compared with the added starter strains used for both cheeses. The initial mixed Lactococcus lactis community seen in the raw milk by DGGE analysis was quite different from the final community seen in the fully ripened cheese, suggesting a selection through processing. We identified at least 3 bands in the V4V5 DGGE profile as Lactococcus lactis in the starter (consistent with the 3 known subspecies present) and only 1 band of Lactococcus lactis in the raw milk; the 3 Lactococcus lactis bands were found through the cheese production process. However, only 1 band of Lactococcus lactis identified both in milk and starter culture was on the final cheese, suggesting differing strain characteristics. From the cultured bacteria (Table 2), we identified the Lactococcus isolates from the raw milk and all parts of the matured cheese as Lactococcus lactis ssp. lactis. The source of the Lc. lactis ssp. lactis in the final mature cheese in both core and veins and rind was examined by comparison of the mature cheese isolates with isolates obtained from the starter cultures using SmaI PFGE. Whereas isolates from the rind showed similarity to starter cultures used in the production, particularly Lactococcus lactis ssp. cremoris, the isolates in the core and veins were quite different. Rind isolates could have been reintroduced to the surface from handling during ripening (more likely as strains matching 2 different starter sources were evident), whereas isolates in the core and veins are more likely to have been present in the milk and survived the fermentation process. This is significant, as the latter may have novel characteristics important for product quality and could be potential starter cultures for this cheese production.

Lactobacillus species were cultured from the milk and were detected through the process (premilling, postmilling and salting, prepiercing, and postpiercing) into the mature cheese by V3 and V4V5 amplification. However, whereas Lactobacillus plantarum was isolated by culture and identified by DGGE analysis through the entire process, Lactobacillus curvatus was isolated only in the raw milk and was not detected through the processing stages, which was an interesting finding because its presence is related to undesirable biofilm formation (Somers et al., 2001) and gas production (Porcellato et al., 2015). In contrast, Lactobacillus casei/paracasei was detected by V3 DGGE only on culture plates from the mature cheese. Thus, Lactobacillus plantarum in the matured cheese is likely to have originated from the raw milk, but the source of Lactobacillus casei/paracasei is unclear. Lactobacillus plantarum has an important role not only in flavor development (Amarita et al., 2001), but has also been shown to inhibit Listeria monocytogenes in a smear-surface soft cheese (Ennahar et al., 1998) and Staphylococcus aureus as well as Salmonella Typhimurium in Montasio cheese (Stecchini et al., 1991). Presence of Lactobacillus plantarum in both the core and the rind of the mature cheese could therefore constitute an important biocontrol aspect, particularly in a raw milk cheese where pathogens are not eliminated by pasteurization.

Enterococcus faecalis and Enterococcus durans have previously been reported in cheeses (Ercolini et al., 2003; Delcenserie et al., 2014; Bulajic et al., 2015); however, their presence in cheese is controversial. According to Gelsomino et al. (2001), Enterococcus faecalis in cheese is usually assumed to be from fecal contamination, and its presence is undesirable because it can cause urinary tract infections in immune-compromised patients (Coque et al., 1996). A study on enterococci in milk products (Gimenez-Pereira, 2005) revealed that enterococci strains from food are generally free from toxigenic potential in humans, which is different from enterococci strains from clinical sources. However, GimenezPereira (2005) advised that the enterococcal levels in milk products should not exceed $10^{7} \mathrm{cfu} / \mathrm{g}$ and good manufacturing practices were needed, specifically in the ripening period when high enterococcal levels were detected. On the other hand, this species contributes to taste and flavor development through proteolysis, lipolysis, and citrate breakdown (Foulequié Moreno et al., 2006). It is noticeable that we detected Enterococcus faecalis in the mature raw milk blue-veined cheese both by DGGE and culturing. We found no evidence of these organisms at other processing stages, which suggests these populations may develop toward the end of the ripening period when the $\mathrm{pH}$ rises.

Staphylococcus equorum was found in the rind prepiercing, when the cheese was ripened at $21^{\circ} \mathrm{C}$, and introduced into the core by the piercing process, although it could only be cultured from culture plates of the rind of the mature cheese. This suggests this species is $\mathrm{pH}$ sensitive, as the core was $\mathrm{pH} 3.6$ prepiercing in comparison to the rind $\mathrm{pH}$ of 4.72 ; the organism appears not to have survived exposure to this low $\mathrm{pH}$, re- 
sulting in its subsequent absence from the core and vein samples of the mature cheese, even though their final $\mathrm{pH}$ was higher $(\mathrm{pH}$ 6.36). These observations support the finding that the growth of Staphylococcus equorum could be increased by increasing the $\mathrm{pH}$ from 4.0 to 6.0 and increasing the temperature from 10 to $26^{\circ} \mathrm{C}$ (Søndergaard and Stahnke, 2002). Staphylococcus equorum is a well-known starter culture in traditional sausage and ham production (Leroy et al., 2009; Landeta et al., 2011). It could inhibit Listeria monocytogenes (Carnio et al., 2000), and, in Tilsit cheese, the combination of Staphylococcus equorum and Debaryomyces hansenii inhibited the growth of undesirable mold (Bockelmann, 2002). The other staphylococci found was Staphylococcus gallinarum; it was detected in the raw milk sample only (Table 2), indicating that this bacterium could not survive the fermentation process. Staphylococcus gallinarum was previously reported from chickens and a pheasant (Devriese et al., 1983), although it has been isolated from both heathy humans (Ohara-Nemoto et al., 2008) and clinical patients (Morfin-Otero et al., 2012).

In Stilton and other mold-ripened cheeses, the $\mathrm{pH}$ of the outer rind is usually higher than that of the inner regions, indicating greater mold growth in the rind than in the core, as would be expected for these aerobic organisms. During fermentation, LAB produce acid, causing the $\mathrm{pH}$ to drop, but as the molds grow these break down proteins to produce ammonia and use the lactic acid, causing the $\mathrm{pH}$ to rise again. From our preliminary findings, the $\mathrm{pH}$ of the rind of 3 commercial Stilton cheeses was in the range 6.5 to 7.1 (unpublished data), whereas the $\mathrm{pH}$ of the raw milk cheese rind was at a higher level of $\mathrm{pH}$ 8.21. It was surprising, therefore, that the RBCA counts from the rind were lower than those of the core. This may represent a difference in the mold species growing or the extent to which they grow during the ripening period. The evaluation of yeast and fungal isolates was not part of this study, but in Stilton these have been shown to be important components for final cheese characteristics (Gkatzionis et al., 2013, 2014).

We also noted that the bacterial diversity of the cheese was more complex than that reported previously for Stilton, which is made with pasteurized milk (Ercolini et al., 2003); this process brings about changes in protein conformation and denaturation that may have an effect on the species that may grow as well as removing the heat sensitive components of the microbiota. Among the raw milk cheese bacterial community, we identified Brevibacterium sp., Halomonas sp., Acinetobacter sp., Alkalibacterium sp., and Corynebacterium casei. These microorganisms are salt-tolerant, less acidtolerant, and have been found in the smear of surface- ripened cheeses, where they contribute to the sensory characteristics produced (Rattray and Fox, 1999; Maoz et al., 2003; Mounier et al., 2005, 2007). The presence of Halomonas is likely to be from salt addition, and these appear to have grown optimally during ripening when a presumably suitable environment had been reached. The presence of Halomonas sp. is considered an indicator of process hygiene (Maoz et al., 2003), but it is also found in smear ripened cheese (Mounier et al., 2005), and the influence of Halomonas sp. on final cheese characteristics would warrant further study. Alkalibacterium has previously been reported from mold-ripened cheeses, with sea salt a suggested route of introduction (Ishikawa et al., 2007). The development of an alkaline $\mathrm{pH}$ in the mature cheese rind would explain the late isolation of this moderately halophilic alkaliphile from the mature cheese and its absence from Stilton, where the rind $\mathrm{pH}$ is neutral. Species of this genus produce organic acids (lactic, formic, and acetic) and ethanol from glucose fermentation (Ishikawa et al., 2009), and thus could be active contributors to matured cheese characteristics. However, cultural isolation of this organism would require more specialist conditions than used here (Ishikawa et al., 2007), indicating the value of the non-culture-based approach. Brevibacterium and Corynebacterium, although widely found in cheese production, are genera associated with the skin and may have been introduced to the cheese surface during handling of the cheese for turning; this concurs with these being found only associated with the rind. Acinetobacter species have been isolated from raw cow milk and raw cow milk cheeses (Rafei et al., 2015), suggesting this species was derived from the raw milk used in production.

All these surface-ripening bacteria were detected using different amplimers, demonstrating the value of analyzing $16 \mathrm{~S}$ regions of mixed bacterial populations with more than one primer set. This could introduce a bias in the interpretation of $16 \mathrm{~S}$ rDNA sequencing results depending on the primer set used. Most metagenomics studies of cheese populations using next-generation sequencing focus on targeting $16 \mathrm{~S}$ rRNA genes using universal primers and so primer bias cannot be discounted, although the high number of reads may be favorable for identifying species present at low levels (Bokulich and Mills, 2012).

\section{CONCLUSIONS}

The bacterial composition of this raw milk blueveined cheese was more complex than that of Stilton cheese. These bacteria are likely to have originated from the raw milk, salt, and handling. We also showed how the piercing process can introduce surface bacteria 
into the core of the cheese during the ripening process, although survival in the core may be dependent on the $\mathrm{pH}$ conditions at the time of introduction. Lactobacillus casei/paracasei, Staphylococcus equorum, Bacillus sp., Brevibacterium sp., Halomonas sp., Acinetobacter sp., Alkalibacterium sp., and Corynebacterium casei were only found by molecular methods. However, using different primers to analyze the $16 \mathrm{~S}$ regions picked up different groups, showing the advantage of using various primers to examine mixed bacterial population. Also, culturing was still valuable as it demonstrated viability of particular groups and detected a large number of raw milk microbiota. It was notable that Lactococcus lactis ssp. lactis was viable in the core and rind of the final cheese and some of these isolates originated from the raw milk.

\section{ACKNOWLEDGMENTS}

The first author gratefully thanks The University of Nottingham and Directorate General of Resources for Science, Technology and Higher Education (DGRSTHE, formerly known as DGHE) Ministry of Research, Technology and Higher Education of Indonesia for financial support. The authors also thank Randolph Hodgson and Joe Schneider from Stichelton Dairy Ltd. (Nottinghamshire, UK) for their assistance in this study and allowing sampling of the cheese production unit.

\section{REFERENCES}

Amarita, F., T. Requena, G. Taborda, L. Amigo, and C. Pelaez. 2001. Lactobacillus casei and Lactobacillus plantarum initiate catabolism of methionine by transamination. J. Appl. Microbiol. 90:971-978. https://doi.org/10.1046/j.1365-2672.2001.01331.x.

Bockelmann, W. 2002. Development of defined surface starter cultures for the ripening of smear cheeses. Int. Dairy J. 12:123-131. https://doi.org/10.1016/S0958-6946(01)00152-2.

Bockelmann, W. 2010. Secondary cheese starter cultures. Pages 193230 in Technology of Cheesemaking. 2nd ed. B. A. Law and A. Y. Tamime, ed. Wiley-Blackwell, Hoboken, NJ.

Bokulich, N. A., and D. A. Mills. 2012. Next-generation approaches to the microbial ecology of food fermentations. BMB Rep. 45:377389. https://doi.org/10.5483/BMBRep.2012.45.7.148.

Bulajic, S., Z. Tambur, D. Opacic, B. Miljkovic-Selimovic, R. Doder, and D. Cenic-Milosevic. 2015. Characterization of antibiotic resistance phenotypes and resistance genes in Enterococcus spp. isolated from cheeses. Arch. Biol. Sci. 67:139-146. https://doi.org/10 .2298/ABS140426016B.

Carnio, M. C., A. Höltzel, M. Rudolf, T. Henle, G. Jung, and S. Scherer. 2000. The macrocyclic peptide antibiotic micrococcin P1 is secreted by the food-borne bacterium Staphylococcus equorum WS 2733 and inhibits Listeria monocytogenes on soft cheese. Appl. Environ. Microbiol. 66:2378-2384. https://doi.org/10.1128/AEM .66.6.2378-2384.2000.

Cocolin, L., M. Manzano, C. Cantoni, and G. Comi. 2001. Denaturing gradient gel electrophoresis analysis of the $16 \mathrm{~S}$ rRNA gene V1 Region to monitor dynamic changes in the bacterial population during fermentation of Italian sausages. Appl. Environ. Microbiol. 67:5113-5121. https://doi.org/10.1128/AEM.67.11.5113-5121 .2001 .
Collins, C., J. Grange, P. Lyne, and J. Falkinham III. 2004. Collins and Lyne's Microbiological Methods. 8th ed. Arnold Publishers. London, United Kingdom.

Conte, A., I. Brescia, and M. A. Del Nobile. 2011. Lysozyme/EDTA disodium salt and modified-atmosphere packaging to prolong the shelf life of Burrata cheese. J. Dairy Sci. 94:5289-5297. https://doi .org/10.3168/jds.2010-3961.

Coque, T. M., J. Tomayko, S. Ricke, P. Okhyusen, and B. Murray. 1996. Vancomycin-resistant enterococci from nosocomial, community, and animal sources in the United States. Antimicrob. Agents Chemother. 40:2605-2609.

Delcenserie, V., B. Taminiau, L. Delhalle, C. Nezer, P. Doyen, S. Crevecoeur, D. Roussey, N. Korsak, and G. Daube. 2014. Microbiota characterization of a Belgian protected designation of origin cheese, Herve cheese, using metagenomic analysis. J. Dairy Sci 97:6046-6056. https://doi.org/10.3168/jds.2014-8225.

Devriese, L. A., B. Poutrel, R. Kilpper-Balz, and K. H. Schleifer. 1983 Staphylococcus gallinarum and Staphylococcus caprae, two new species from animals. Int. J. Syst. Bacteriol. 33:480-486. https://doi .org/10.1099/00207713-33-3-480.

El-Baradei, G., A. Delacroix-Buchet, and J.-C. Ogier. 2007. Biodiversity of bacterial ecosystems in traditional Egyptian Domiati cheese. Appl. Environ. Microbiol. 73:1248-1255. https://doi.org/ 10.1128/AEM.01667-06.

Ennahar, S., O. Assobhei, and C. Hasselmann. 1998. Inhibition of Listeria monocytogenes in a smear-surface soft cheese by Lactobacillus plantarum WHE 92, a pediocin AcH producer. J. Food Prot. 61:186-191. https://doi.org/10.4315/0362-028X-61.2.186.

Ercolini, D., P. J. Hill, and C. E. R. Dodd. 2003. Bacterial community structure and location in Stilton cheese. Appl. Environ. Microbiol. 69:3540-3548. https://doi.org/10.1128/AEM.69.6.3540-3548.2003.

Ercolini, D., G. Mauriello, G. Blaiotta, G. Moschetti, and S. Coppola. 2004. PCR-DGGE Fingerprints of microbial succession during a manufacture of traditional water buffalo Mozzarella cheese. J. Appl. Microbiol. 96:263-270. https://doi.org/10.1046/j.1365-2672 2003.02146.x

Flórez, A. B., and B. Mayo. 2006. PCR-DGGE as a tool for characterizing dominant microbial populations in the Spanish blue-veined Cabrales cheese. Int. Dairy J. 16:1205-1210. https://doi.org/10 .1016/j.idairyj.2005.11.008.

Foulequié Moreno, M. R., P. Sarantinopoulos, E. Tsakalidou, and L. De Vuyst. 2006. The role and application of enterococci in food and health. Int. J. Food Microbiol. 106:1-24. https://doi.org/10 $.1016 /$ j.ijfoodmicro.2005.06.026.

Gelsomino, R., M. Vancanneyt, S. Condon, J. Swings, and T. M. Cogan. 2001. Enterococcal diversity in the environment of an Irish cheddar-type cheesemaking factory. Int. J. Food Microbiol. 71:177-188. https://doi.org/10.1016/S0168-1605(01)00620-1.

Gimenez-Pereira, M. L. 2005. Enterococci in milk products. MS thesis. Veterinary Studies, Massey University, New Zealand.

Gkatzionis, K., L. Hewson, T. Hollowood, J. Hort, C. E. R. Dodd, and R. S. T. Linforth. 2013. Effect of Yarrowia lipolytica on blue cheese odour development: Flash profile sensory evaluation of microbiological models and cheeses. Int. Dairy J. 30:8-13. https://doi.org/ 10.1016/j.idairyj.2012.11.010

Gkatzionis, K., D. Yunita, R. S. T. Linforth, M. Dickinson, and C. E. R. Dodd. 2014. Diversity and activities of yeasts from different parts of a Stilton cheese. Int. J. Food Microbiol. 177:109-116. https://doi.org/10.1016/j.ijfoodmicro.2014.02.016.

Gori, K., H. D. Mortensen, N. Arneborg, and L. Jespersen. 2007. Ammonia production and its possible role as a mediator of communication for Debaryomyces hansenii and other cheese-relevant yeast Species. J. Dairy Sci. 90:5032-5041. https://doi.org/10.3168/jds .2006-750.

Gould, L. H., E. Mungai, and C. B. Behravesh. 2014. Outbreaks attributed to cheese: Differences between outbreaks caused by unpasteurized and pasteurized dairy products, United States, 19982011. Foodborne Pathog. Dis. 11:545-551. https://doi.org/10 $.1089 /$ fpd.2013.1650.

Ishikawa, M., K. Kodama, H. Yasuda, A. Okamoto-Kainuma, K. Koizumi, and K. Yamasato. 2007. Presence of halophilic and alkali- 
philic lactic acid bacteria in various cheeses. Lett. Appl. Microbiol. 44:308-313. https://doi.org/10.1111/j.1472-765X.2006.02073.x.

Ishikawa, M., S. Tanasupawat, K. Nakajima, H. Kanamori, S. Ishizaki, K. Kodama, A. Okamoto-Kainuma, Y. Koizumi, Y. Yamamoto, and K. Yamasato. 2009. Alkalibacterium thalassium sp. nov., Alkalibacterium pelagium sp. nov., Alkalibacterium putridalgicola sp. nov. and Alkalibacterium kapii sp. nov., slightly halophilic and alkaliphilic marine lactic acid bacteria isolated from marine organisms and salted foods collected in Japan and Thailand. Int. J. Syst. Evol. Microbiol. 59:1215-1226. https://doi.org/10.1099/ijs.0 .65602-0.

Kafili, T., S. H. Razavi, Z. E. Djomeh, M. R. Naghavi, P. ÁlvarezMartín, and B. Mayo. 2009. Microbial characterization of Iranian traditional Lighvan cheese over manufacturing and ripening via culturing and PCR-DGGE analysis: Identification and typing of dominant lactobacilli. Eur. Food Res. Technol. 229:83-92. https:// doi.org/10.1007/s00217-009-1028-x.

Kang, Y. J., J. Cheng, L. J. Mei, J. Hu, Z. Piao, and S. X. Yin. 2010. Multiple copies of $16 \mathrm{~S}$ rRNA gene affect the restriction patterns and DGGE profile revealed by analysis of genome database. Microbiology 79:664-671. https://doi.org/10.1134/S0026261710050103.

Landeta, G., I. Reverón, A. V. Carrascosa, B. de las Rivas, and R. Muñoz. 2011. Use of recA gene sequence analysis for the identification of Staphylococcus equorum strains predominant on dry-cured hams. Food Microbiol. 28:1205-1210. https://doi.org/10.1016/j.fm .2011.04.006.

Leroy, S., I. Lebert, J.-P. Chacornac, P. Chavant, T. Bernardi, and R. Talon. 2009. Genetic diversity and biofilm formation of Staphylococcus equorum isolated from naturally fermented sausages and their manufacturing environment. Int. J. Food Microbiol. 134:4651. https://doi.org/10.1016/j.ijfoodmicro.2008.12.012.

Lorbeg, P. M., A. Č. Majhenič, and I. Rogelj. 2009. Evaluation of different primers for PCR-DGGE analysis of cheese-associated enterococci. J. Dairy Res. 76:265-271. https://doi.org/10.1017/ S0022029909003902.

Maoz, A., R. Mayr, and S. Scherer. 2003. Temporal stability and biodiversity of two complex antilisterial cheese-ripening microbial consortia. Appl. Environ. Microbiol. 69:4012-4018. https://doi.org/10 .1128/AEM.69.7.4012-4018.2003.

McSweeney, P. L. H., and P. F. P. Fox. 2004. Metabolism or residual lactose and of lactate and citrate. Pages 361-371 in Cheese: Chemistry, Physics and Microbiology Vol. 1. P. F. Fox, P. L. H. McSweeney, T. M. Cogan, and T. P. Guinee, ed. Academic Press, London, UK.

Montel, M.-C., S. Buchin, A. Mallet, C. Delbes-Paus, D. A. Vuitton, N. Desmasures, and F. Berthier. 2014. Traditional cheeses: Rich and diverse microbiota with associated benefits. Int. J. Food Microbiol. 177:136-154. https://doi.org/10.1016/j.ijfoodmicro.2014 .02 .019 .

Morfin-Otero, R., M. A. Martínez-Vázquez, D. López, E. RodríguezNoriega, and E. Garza-González. 2012. Isolation of rare coagulasenegative isolates in immunocompromised patients: Staphylococcus gallinarum, Staphylococcus pettenkoferi and Staphylococcus pasteuri. Ann. Clin. Lab. Sci. 42:182-185.

Mounier, J., R. Gelsomino, S. Goerges, M. Vancanneyt, K. Vandemeulebroecke, B. Hoste, S. Scherer, J. Swings, G. F. Fitzgerald, and T. M. Cogan. 2005. Surface microflora of four smear-ripened cheeses. Appl. Environ. Microbiol. 71:6489-6500. https://doi.org/ 10.1128/AEM.71.11.6489-6500.2005.

Mounier, J., F. Irlinger, M.-N. Leclercq-Perlat, A.-S. Sarthou, H.-E. Spinnler, G. F. Fitzgerald, and T. M. Cogan. 2006. Growth and colour development of some surface ripening bacteria with $D e-$ baryomyces hansenii on aseptic cheese curd. J. Dairy Res. 73:441448. https://doi.org/10.1017/S0022029906001919.

Mounier, J., M. C. Rea, P. M. O'Connor, G. F. Fitzgerald, and T. M. Cogan. 2007. Growth characteristics of Brevibacterium, Corynebacterium, Microbacterium, and Staphylococcus spp. isolated from surface-ripened cheese. Appl. Environ. Microbiol. 73:7732-7739. https://doi.org/10.1128/AEM.01260-07.
Muyzer, G., E. C. D. E. Waal, and A. G. Uitierlinden. 1993. Profiling of complex microbial populations by denaturing gradient gel electrophoresis analysis of polymerase chain reaction-amplified genes coding for 16S rRNA. Appl. Environ. Microbiol. 59:695-700.

NanoDrop Technologies Inc. 2007. 260/280 and 260/230 Ratios NanoDrop ND-1000 and ND-8000 8-Sample Spectrophotometers. NanoDrop Technologies, Wilmington, DE.

Nübel, U., B. Engelen, A. Felske, J. Snaidr, A. Wieshuber, R. I. Amann, W. Ludwig, and H. Backhaus. 1996. Sequence heterogeneities of genes encoding 16S rRNAs in Paenibacillus polymyxa detected by temperature gradient gel electrophoresis. J. Bacteriol. 178:5636-5643. https://doi.org/10.1128/jb.178.19.5636-5643.1996.

Obodai, M. A. B. 2006. Characterisation of the dominant microbiota in Nyamie, a Ghananian fermented milk product. PhD Thesis. Food Sciences, The University of Nottingham, Nottingham, United Kingdom.

Obszanska, K., I. Kern-Zdanowicz, and I. Sitkiewicz. 2015. Optimized protocol for PFGE analysis of Anginosus (milleri). Streptococci. Polish J. Microbiol. 64:61-64.

Ohara-Nemoto, Y., H. Haraga, S. Kimura, and T. K. Nemoto. 2008. Occurrence of staphylococci in the oral cavities of healthy adults and nasal oral trafficking of the bacteria. J. Med. Microbiol. 57:9599. https://doi.org/10.1099/jmm.0.47561-0.

Porcellato, D., M. E. Johnson, K. Houck, S. B. Skeie, D. A. Mills, K. M. Kalanetra, and J. L. Steele. 2015. Potential of Lactobacillus curvatus LFC1 to produce slits in cheddar cheese. Food Microbiol. 49:65-73. https://doi.org/10.1016/j.fm.2015.01.015.

Price, E. J., R. S. T. Linforth, C. E. R. Dodd, C. A. Phillips, L. Hewson, J. Hort, and K. Gkatzionis. 2014. Study of the influence of yeast inoculum concentration (Yarrowia lipolytica and Kluyveromyces lactis) on blue cheese aroma development using microbiological models. Food Chem. 145:464-472. https://doi.org/10.1016/ j.foodchem.2013.08.081.

Qiagen. 2018. DNeasy mericon food handbook. Accessed Feb. 28, 2018. https://www.qiagen.com/ $\mathrm{mx} /$ resources/resourcedetail?id= d0e372d7-6f6a-415e-9d72-297a53d95854\&lang=en .

Rafei, R., M. Hamze, H. Pailhories, M. Eveillard, L. Marsollier, M. L. Joly-Guillou, F. Dabboussi, and M. Kempf. 2015. Extrahuman epidemiology of Acinetobacter baumannii in Lebanon. Appl. Environ. Microbiol. 81:2359-2367. https://doi.org/10.1128/AEM.03824-14.

Randazzo, C. L., S. Torriani, A. D. L. Akkermans, W. M. de Vos, and E. E. Vaughan. 2002. Diversity, dynamics, and activity of bacterial communities during production of an artisanal Sicilian cheese as evaluated by $16 \mathrm{~S}$ rRNA analysis. Appl. Environ. Microbiol. 68:1882-1892. https://doi.org/10.1128/AEM.68.4.1882-1892.2002.

Rattray, F. P., and P. F. Fox. 1999. Aspects of enzymology and biochemical properties of Brevibacterium linens relevant to cheese ripening: a review. J. Dairy Sci. 82:891-909. https://doi.org/10.3168/ jds.S0022-0302(99)75308-7.

Schwieger, F., and C. C. Tebbe. 1998. A new approach to utilize PCRpolymorphism for $16 \mathrm{~S}$ rRNA gene-based microbial community analysis. Appl. Environ. Microbiol. 64:4870-4876.

Scott, R., R. K. Robinson, and R. A. Wilbey. 1998. Cheesemaking Practice. 3rd ed. Aspen Publishers Inc., Reading, UK.

Somers, E. B., M. E. Johnson, and A. C. L. Wong. 2001. Biofilm formation and contamination of cheese by nonstarter lactic acid bacteria in the dairy environment. J. Dairy Sci. 84:1926-1936. https://doi.org/10.3168/jds.S0022-0302(01)74634-6.

Søndergaard, A. K., and L. H. Stahnke. 2002. Growth and aroma production by Staphylococcus xylosus, S. carnosus and S. equorum A comparative study in model systems. Int. J. Food Microbiol. 75:99-109. https://doi.org/10.1016/S0168-1605(01)00729-2.

Stecchini, M. L., I. Sarais, and M. De Bertoldi. 1991. The influence of Lactobacillus plantarum culture inoculation on the fate of Staphylococcus aureus and Salmonella typhimurium in Montasio cheese. Int. J. Food Microbiol. 14:99-109. https://doi.org/10.1016/0168 $-1605(91) 90096-8$. 